neo apropiado por cirugía microvascular y un tejido adecuado para el sitio de anastomosis contribuye a mejorar los resultados.

\section{Tres clases de histerectomía vaginal radical para el tratamiento del cáncer endometrial y cervical}

Giambattista Massi, MD, Luciano Savino, MD, and Tommaso Susini, MD

\section{From the Obstetrics and Gynecology Department, University of Florence}

Am J Obstet Gynecol 1996; 175: 1576-1585.

Objetivos: Los propósitos fueron: (1) describir tres tipos de histerectomía vaginal extendida con diferentes grados de radicalidad, (2) identificar posibles indicaciones para cada una de ellas y (3) estimular la individualización del tratamiento, con especial referencia a la reevaluación del papel de la cirugía vaginal en la oncología ginecológica.

Diseño del estudio: Se ilustran los principios quirúrgicosanatómicos de la cirugía vaginal radical y las técnicas de tres histerectomías vaginales con extensión en incremento. Las posibles indicaciones se presentan con base en la experiencia propia de estudios retrospectivos publicados previamente.

Resultados: La clase I de histerectomía vaginal extendida permite la disección «en bloque» del útero junto con el tercio superior de vagina y ambos anexos. No se remueven los parametrios. Este procedimiento ha demostrado ser valioso para el tratamiento del cáncer endometrial Estado I. En la clase II de histerectomía vaginal extendida se preserva el tracto distal de los parametrios anterior y posterior, mientras que se remueve completamente el ligamento cardinal. Esta operación ha mostrado resultados prometedores para el tratamiento del cáncer cervical estados IB-IIA de pequeño volumen mientras que reduce la incidencia de disfunciones vesicales y rectales. Los procedimientos de clase III incluyen la remoción completa de los parametrios (anterior, lateral y posterior). Esta operación ha mostrado que proporciona una alta tasa de curación para el cáncer cervical estados IB-IIA.

Conclusiones: En vista de las múltiples ventajas de la cirugía vaginal, ésta aproximación debe ser considerada para el tratamiento individualizado de casos seleccionados de cánceres endometrial y cervical. Las tres clases de histerectomía vaginal permiten ajustar el tipo de operación a las características clínicas y físicas de las pacientes. El uso combinado de la linfadenectomía extraperitoneal o laparoscópica podrían extender considerablemente las indicaciones para las operaciones vaginales radicales.

\section{Influencia relativa de la edad y la menopausia en los cambios de la composición corporal total y regional en mujeres postmenopáusicas}

Florence A. Trémolliers, $\mathrm{MD}, \mathrm{PhD}$, Jean-Michel Pouilles, $\mathrm{MD}$, and Claude A. Ribot, MD

From the Unité Fonctionnelle Ménopause et Maladies Métaboliques, Service d'Endocrinologie, Centre Hospitalier Universitaire Purpan

Am J Obstet Gynecol 1996; 175: 1594-1600.
Objetivo: Se midió la composición corporal total y regional para evaluar las diferencias en la composición asociadas con la menopausia y para determinar si los cambios en la distribución de la grasa estaban más relacionadas con la edad o con la menopausia.

Diseño del estudio: Se estudiaron 205 mujeres blancas saludables quienes no habían recibido terapia de reemplazo estrogénico de acuerdo con el estado menopáusico y la edad. La masa ósea y la composición corporal se midieron por absorciometría dual con rayos X. Se calcularon las proporciones de grasa androide y ginecoide en todas las mujeres y se investigaron las diferencias por análisis estadísticos.

Resultados: Comparadas con las mujeres premenopáusicas, las mujeres posmenopáusicas se caracterizaron por un aumento significativo en la proporción de grasa androide y en la relación grasa del tronco/grasa de la pierna, mientras que la cantidad absoluta de masa corporal grasa no cambia significativamente. Las diferentes variables de distribución androide de la grasa tienden a correlacionarse mejor con los años desde la menopausia que con la edad. En el análisis de regresión múltiple, los años desde la menopausia fueron un predictor de la masa corporal grasa y grasa del tronco, mientras que la edad no fue predictora de ninguna de las variables de distribución de la grasa.

Conclusiones: Este estudio subraya los cambios tempranos en la distribución de la grasa corporal con una desviación de la grasa corporal hacia una localización mas central en la mujer posmenopáusica. Este cambio en la distribución de la grasa parece estar mas relacionado con la menopausia que con la edad y podría, junto con otros factores, contribuir a explicar el aumento del riesgo cardiovascular informado en mujeres posmenopáusicas.

\section{Respuesta inmune específica contra hemolisina de Gardnerella vaginalis en pacientes con vaginosis bacteriana}

Sabina Cauci, $\mathrm{PhD},{ }^{\mathrm{a}}$ Federica Scrimin, MD, ${ }^{\mathrm{b}}$ Silvia Driussi, MD, ${ }^{c}$ Sandro Ceccone, MS, ${ }^{a}$ Rossella Monte, MS, ${ }^{a}$ Loris Fant, MS, ${ }^{\mathrm{d}}$ and Franco Quadrifoglio, $\mathrm{PhD}^{\mathrm{a}}$

From the Department of Biomedical Sciences and Technologies, School of Medicine, University of Udine, ${ }^{a}$ the Institute of Obstetrics and Gynecology, Istituto di

Ricovero e Cura a Carattere Scientifico "Burlo

Garofolo," Azienda Sanitaria Locale 4, " and the Microbiology Unit, San Daniele Hospital ${ }^{d}$

Am J Obstet Gynecol 1996; 175: 1601-1605.

Objetivo: Estudiar la respuesta mucosa del hospedero en vaginosis bacteriana evaluando la presencia de una respuesta inmune específica contra la hemolisina deGardnerella vaginalis en fluidos vaginales de pacientes y verificar su correlación con los criterios adoptados para diagnosticar la vaginosis bacteriana.

Diseño del estudio: Se incluyeron un total de 123 mujeres blancas que consultaron a una unidad de cuidado ginecológico por quejas urogenitales o para tamizaje de cáncer uterino (prueba de Papanicolaou), con edades entre 20 y 60 años y no menstruando. La vaginosis bacteriana se diagnosticó por criterios clínicos y un puntaje de la tinción de Gram $>6$. 